7. Reprod. Fertil. (1963) 5, 13-22

\title{
EFFECTS OF ALKYLATING AGENTS ON SPERMATOGENESIS IN THE RABBIT
}

\author{
B. W. FOX, H. JAGKSON, A. W. CRAIG AND T. D. GLOVER \\ Department of Experimental Chemotherapy, Christie Hospital, Manchester 20, and \\ Department of Veterinary Anatomy, University of Liverpool
}

(Received 26th Fune 1962)

\begin{abstract}
Summary. Serial sperm counts have been made in rabbits treated with alkylating agents. After single injections of Busulphan, Tretamine and isopropyl methanesulphonate, aspermia developed during the 10 th and 11 th weeks. Other simple monofunctional esters of methane and ethane sulphonic acids, which induced sterility in rats as a result of their action on spermatozoa and late spermatids, did not depress the sperm count or interfere with sperm motility in the rabbit. The results suggest that the duration of spermatogenesis in the rabbit is about 10 weeks and indicate that in this species, as in rats and mice, a steady turnover of spermatozoa occurs. Fertility tests in male rabbits after administration of Tretamine showed that small doses readily induced sterility which could be maintained by continued administration.
\end{abstract}

\section{INTRODUCTION}

It has been shown that a number of alkylating agents which may or may not be capable of inhibiting experimental tumours can produce selective effects on spermatogenesis (Jackson, Fox \& Craig, 1959, 1961). Thus in male rats and mice serial weekly matings after treatment reveal characteristic phases of sterility which are related to the affected phase of spermatogenesis (Jackson et al., 1959, 1961). The sterility may be due to selective damage to early germ cells or to an action on spermatids or morphologically mature spermatozoa in the testis and epididymis. In the former case, the sperm content of vaginal smears found after mating with the treated males indicated oligospermia or aspermia. Where interference with late phases of spermatogenesis is involved, the vaginal smears after insemination appeared to contain the usual abundance of motile spermatozoa. In the latter circumstances, there was no definite evidence whether or not the number or morphology of spermatozoa had been affected. It was largely for this reason that experiments with rabbits were undertaken.

\section{MATERIALS AND METHODS}

EXPERIMENTAL ANIMALS

The rabbits used were of Dutch and English breeds, 2 to $3 \mathrm{~kg}$ in weight and maintained on standard SG1 rabbit and guinea-pig pellets (Mill Hill formulation) with water ad libitum. The diet was supplemented once weekly with fresh carrots or cabbage. 
Five drugs have so far been examined, namely, Tretamine ( $\mathrm{N} \mathrm{N}^{\prime} \mathrm{N}^{\prime \prime}$ triethylenemelamine) (TEM), Busulphan (Myleran, 1,4 dimethanesulphonoxybutane) methyl ethanesulphonate $\left(\mathrm{C}_{2} \mathrm{H}_{5} . \mathrm{SO}_{2} \cdot \mathrm{OCH}_{3}\right)$ (MEs), methyl methanesulphonate $\left(\mathrm{CH}_{3} \cdot \mathrm{SO}_{2} \cdot \mathrm{OCH}_{3}\right)$ (MMs) and isopropyl methanesulphonate $\left(\mathrm{CH}_{3} \cdot \mathrm{SO}_{2} \cdot \mathrm{OCH}\left(\mathrm{CH}_{3}\right)_{2}\right)$ (IMs). It would be desirable to correlate the sperm count with fertility in rabbits, but because of the technical problems involved only fertility results with Tretamine are so far available.

\section{GOLLECTION OF SEMEN}

Ejaculated semen was collected by means of an artificial vagina (Macirone \& Walton, 1938; Walton, 1958) with a modification described by Glover (1959). Specimens were obtained regularly twice a week. Only rabbits providing control values for at least 6 weeks before treatment were used. These values were usually in the range 5 to $25 \times 10^{7}$ spermatozoa per ejaculate, with a volume varying between 0.10 and $0.90 \mathrm{ml}$. The gel accompanying the sperm-

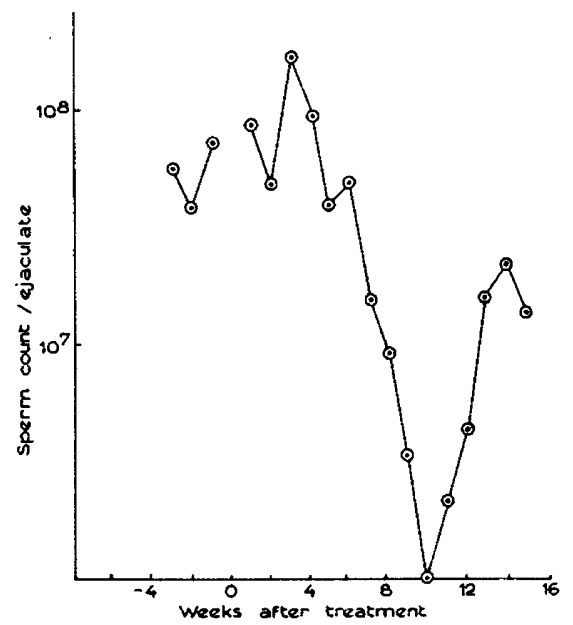

TEXT-FIC. 1. Mean weekly sperm count per ejaculate after treatment with a single dose of TEM $(0.2 \mathrm{mg} / \mathrm{kg}$ intravenously in saline solution). The development of aspermia in the 10 th week is seen, corresponding probably to an action of the drug on spermatogonia.

atozoa in the ejaculates of some rabbits could be removed with forceps and did not contain a significant number of spermatozoa. An aliquot of $0.1 \mathrm{ml}$ was taken from each sample and diluted to $20 \mathrm{ml}$ with approximately $0.5 \%$ formolsaline solution. Counts were made in the Fuchs-Rosenthal haemocytometer. The morphology of fresh spermatozoa was examined using the nigrosin-eosin differential stain (Glover, 1960).

\section{FERTILITY TEST}

Bucks of proven fertility were used. They were treated with various dose levels of TEM and were mated consecutively once weekly with does, also of proven fertility. Since relatively large numbers of females of proven fertility were 


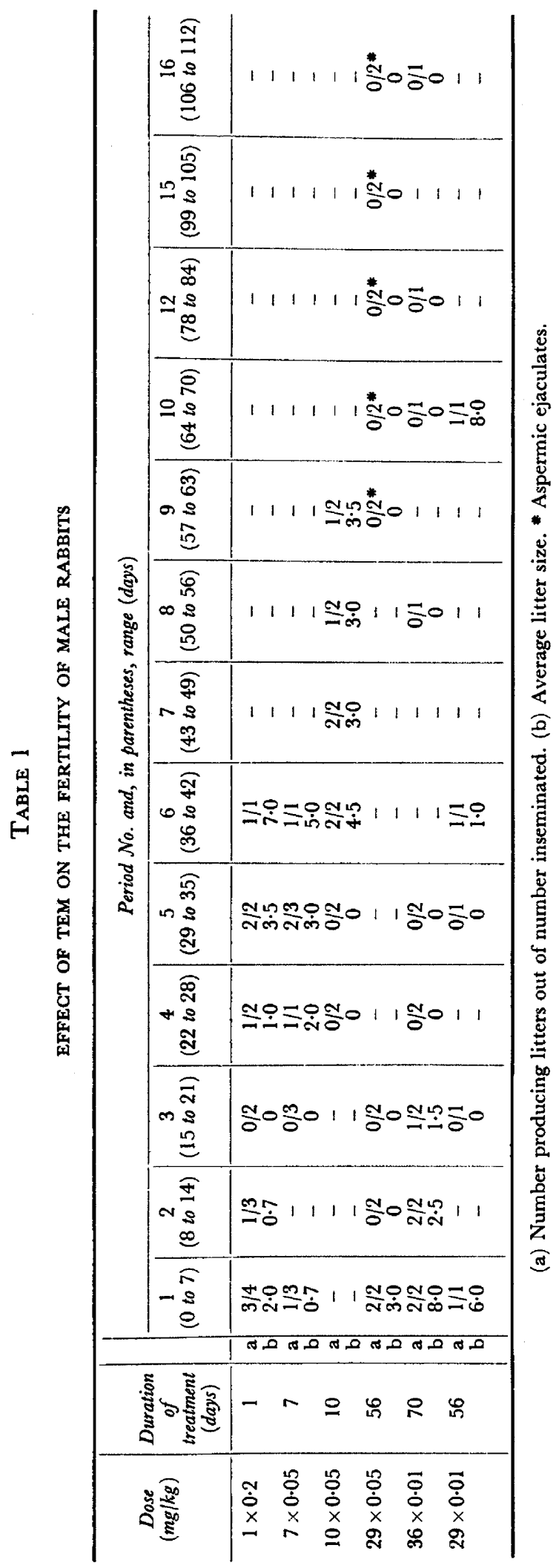


required for these experiments, it was found necessary to use females again, after an interval of not less than 2 months.

\section{RESULTS}

TRETAMINE

A single intravenous dose $(0.2 \mathrm{mg} / \mathrm{kg})$ in saline solution had no effect for 7 weeks, after which the sperm count progressively declined to aspermia in the 10th week (Text-fig. 1). Recovery commenced in Week 11 and had approached normal levels by the 13th week. Fertility tests indicated that a sterile period occurred in the 3rd week, with a period of subfertility before and after the infertile stage (Table 1). There was, however, no alteration in sperm count

TABLE 2

TOTAL PERCENTAGE SPERMATOZOAL ABNORMALITIES IN RABBIT EJAGULATES AFTER TREATMENT

\begin{tabular}{|c|c|c|c|c|}
\hline $\begin{array}{c}\text { Period } \\
\text { (days from treatment) }\end{array}$ & TEM & MMS & MES & IMS \\
\hline $\begin{array}{l}-14 \text { to }-10 \\
-9 \text { to }-5 \\
-4 \text { to } 0 \\
1 \text { to } 4 \\
5 \text { to } 9 \\
10 \text { to } 14 \\
15 \text { to } 19 \\
20 \text { to } 24 \\
25 \text { to } 29 \\
30 \text { to } 34 \\
35 \text { to } 39 \\
40 \text { to } 44 \\
45 \text { to } 49 \\
50 \text { to } 54 \\
55 \text { to } 59 \\
60 \text { to } 64 \\
65 \text { to } 69 \\
70 \text { to } 74\end{array}$ & $\begin{array}{r}8 \\
6 \\
8 \\
7 \\
8 \\
7 \\
9 \\
9 \\
13\end{array}$ & $\begin{array}{r}10 \\
9 \\
9 \\
3 \\
13 \\
14 \\
17 \\
35 \\
\\
33 \\
12\end{array}$ & $\begin{array}{r}7 \\
17 \\
14 \\
8 \\
7 \\
16 \\
12 \\
11 \\
57 \\
28\end{array}$ & $\begin{array}{l}11 \\
12 \\
10\end{array}$ \\
\hline
\end{tabular}

The total percentages of primary and secondary abnormalities after administration of alkylating agent are shown in this Table. These abnormalities are considered (Blom, 1950) to be due to defects occurring within the testes and epididymides, respectively. The incidence of spermatozoa with coiled tails has not been recorded because it is difficult to determine what proportion of them is due to artifacts (Bishop, Campbell, Hancock \& Walton, 1954).

during this time, nor were there any changes in the motility or morphology of spermatozoa (Table 2) which could be correlated with the loss of fertility. There was some evidence, however, of an increased incidence of abnormal spermatozoa from the 40th day onwards.

The routine determination of fertility in the rabbit is more difficult than in the rat. Owing to restricted accommodation, it was only possible to obtain data from a limited number of animals. 
A series of additional fertility tests was undertaken to examine the sensitivity of rabbit spermatogenesis to multiple doses of Tretamine. Seven daily doses of $0.05 \mathrm{mg} / \mathrm{kg}$ intravenously produced temporary sterility in the three treated animals during the 3rd week (Table 1). After ten such doses, both animals were mated from the 4th week onwards. They became sterile within Weeks 4 and 5 of being treated, but later recovered their fertility. More prolonged treatment (twenty-nine doses, $0.05 \mathrm{mg} / \mathrm{kg}$ each; see Table 1) led to infertility from the 2nd week of mating onwards. Sterility was maintained for the remainder of the experiment (duration 16 weeks). Spermatozoa were found in the vagina after each mating until the 9 th week when none was seen. During this latter period, semen collected in the artificial vagina was of average volume, had a superficial cloudy appearance, but contained no spermatozoa. No effect on the libido of either male was noted throughout the experiment. The cumulative action was tested at a lower dose level (thirty-six doses of $0.01 \mathrm{mg} / \mathrm{kg}$ intravenously) and again sterility occurred in both males for at least 20 weeks. A shorter course (twenty-nine doses of $0.01 \mathrm{mg} / \mathrm{kg}$ ) in a single animal, resulted in sterility from the 3rd week of treatment onwards. This animal subsequently recovered its fertility (Table 1).

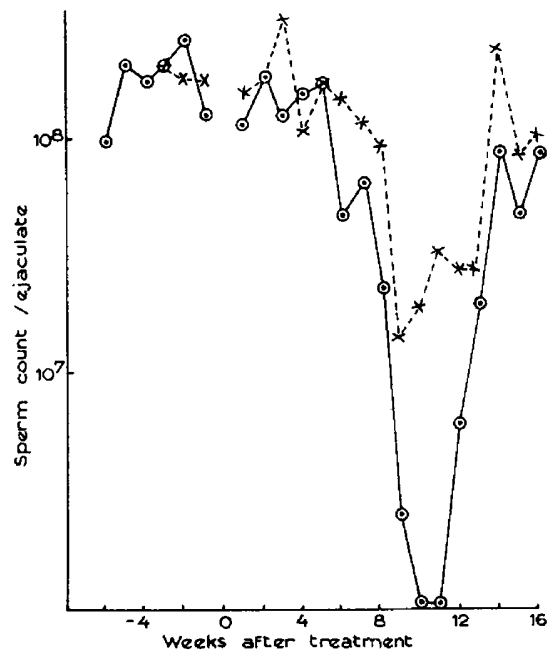

\begin{abstract}
'TExT-FIG. 2. Mean weekly sperm count per ejaculate in the rabbit after treatment with single doses of Busulphan: - - - - $10 \mathrm{mg} / \mathrm{kg}, \longrightarrow 40 \mathrm{mg} / \mathrm{kg}$; given intraperitoneally in Arachis oil. A depression of sperm count occurs between Weeks 9 and 12, with aspermic ejaculates in Weeks 10 and 11 at the higher dose, correlating with an action of the drug on early phases of spermatogenesis.
\end{abstract}

\title{
BUSULPHAN
}

The disulphonic ester was administered intraperitoneally as a finely divided suspension in Arachis oil. A single dose of $10 \mathrm{mg} / \mathrm{kg}$ caused a depression of the spermatozoal count during Weeks 9 to 14 after treatment (Text-fig. 2), whilst $40 \mathrm{mg} / \mathrm{kg}$ produced mean values of less than $10^{6}$ spermatozoa per ejaculate in Weeks 10 and 11 . There was no change in either libido or volume of seminal fluid during the whole period of the experiment. 
This compound was administered intravenously ( $100 \mathrm{mg} / \mathrm{kg}$ ) as a freshly prepared solution $(5 \cdot 8 \mathrm{ml})$ in Sorenson's phosphate buffer $(\mathrm{pH} 7 \cdot 7)$. This procedure was followed because of the relative instability of the compound in aqueous solution (Ross, 1962, quotes a half-life of $13 \mathrm{~min}$ at $37^{\circ} \mathrm{C}$ ) with the production of the strong methane sulphonic acid. The number of spermatozoa

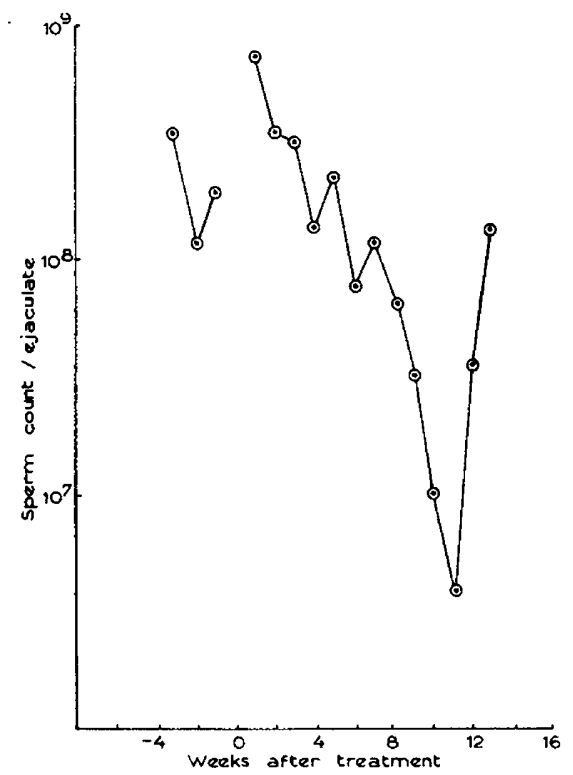

Text-Fig. 3. Mean weekly sperm count per ejaculate after treatment with a single dose of IMS $(100 \mathrm{mg} / \mathrm{kg}$ intravenously in phosphate buffer, $\mathrm{pH} 7 \cdot 7)$. A minimum count occurred during the 10 th to 11 th week corresponding to an action on early stages of spermatogonial development.

began to fall in Week 7 with a minimum value occurring during Week 11 and being followed by a rapid recovery to normal levels (Text-fig. 3). A significant increase in the incidence of abnormal spermatozoa was observed from 45 days onwards.

\section{METHYL ETHANESULPHONATE AND METHYL METHANESULPHONATE}

Neither of these substances in doses close to the maximum tolerated dose produced any significant alteration in sperm count, nor any radical change in the morphology of spermatozoa during the first few weeks after treatment (Textfig. 4). The results support the view of Jackson et al. $(1959,1961)$ that the sterility observed in rats after these substances is not due to oligospermia or the production of morphologically abnormal spermatozoa. Also, they provide additional evidence for the suggestion that these substances do not interfere with spermatogonial development. There was again some evidence in later weeks of an increased incidence of morphological abnormalities in spermatozoa, especially after treatment with MES. 


\section{DISCUSSION}

The assessment of fertility by systematic matings in the rat after treatment with alkylating agents (Bock \& Jackson, 1957; Jackson et al., 1959, 1961) does not adequately distinguish sterility due to oligospermia from that due to other effects on spermatozoa. It is thus desirable to obtain quantitative data regarding

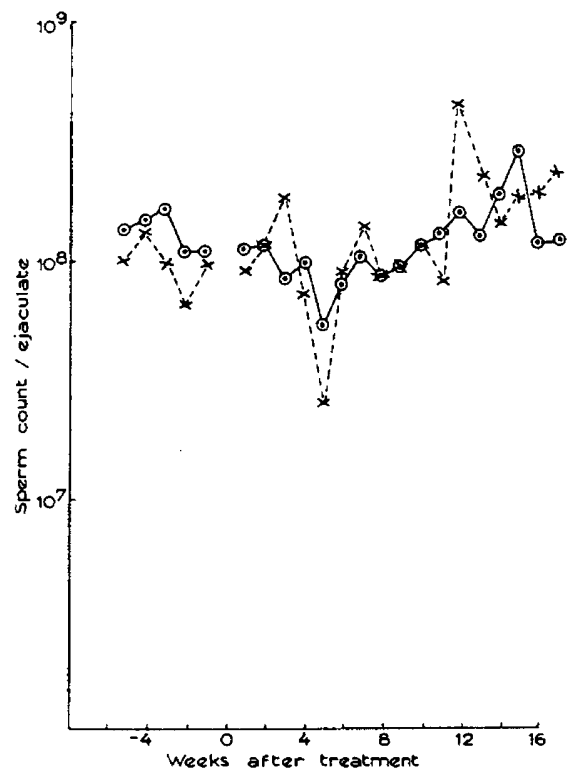

Text-FIG. 4. Mean weekly sperm count per ejaculate in a rabbit after treatment with MES ( $50 \mathrm{mg} / \mathrm{kg}$ intravenously in saline solution). No significant changes occurred in the count. The graph also demonstrated the constancy of the sperm count taken over relatively long periods.

$$
\begin{aligned}
& \times \ldots . . \times \text { MMS }(30 \mathrm{mg} / \mathrm{kg}) \text {. } \\
& \odot-\odot \operatorname{MEs}(50 \mathrm{mg} / \mathrm{kg}) \text {. }
\end{aligned}
$$

the concentration and morphology of spermatozoa after treatment. A satisfactory technique for the collection of ejaculates from rats or mice under relatively normal physiological conditions is not available, but the technique used in the present experiments for rabbits gave consistent and reliable results. Systematic data on the fertility of rabbits is difficult to obtain, and thus any correlation made between the sperm count of this species and that of the fertility of rats, is largely based on accumulating evidence that the time sequence of spermatogenesis and epididymal transport in the two species is of similar duration, i.e. 9 to 10 weeks (Heller, 1948).

Tretamine caused a depletion of spermatozoa in the ejaculates of rabbits 10 weeks after treatment (Text-fig. 2), which is comparable with the observation (Steinberger, Nelson, Boccabella \& Dixon, 1959) that a transient depletion of spermatogonia occurs in the rat after treatment with the same compound. Furthermore, the subfertility observed in experiments with rats (Jackson $e t a l$,, 1961) 9 to 10 weeks after treatment could be accounted for by a similar depletion. There was neither change in sperm morphology nor diminution in the 
sperm count of the rabbit in the 4th week, when sterility evidently occurs both in this species and in the rat. It is thus apparent that the sterility is most likely to be due to some inconspicuous change in the spermatozoa. The term 'dominant lethal mutation' has been used to describe the cause of this TEM-induced sterility in mice (Cattenach \& Edwards, 1958), on the assumption that genetic material within the spermatozoa has been damaged by the alkylating agent.

In order to test the susceptibility of rabbits to the antifertility action of TEM several protracted courses of treatment have been tried in an attempt to determine the minimal dose required to induce and maintain sterility (Table 1). The lowest dose used in our experiments $(0.01 \mathrm{mg} / \mathrm{kg}$ intravenously daily), produced sterility by the 4 th week, and this persisted throughout the experiment. Lower dose levels were not attempted, but clearly, these doses did not represent the minimum that could be expected to induce an effect.

Busulphan selectively inhibits early spermatogonial development in the rat (Jackson et al., 1961) and sterility develops after a delay which corresponds to the duration of spermatogenesis ( 9 to 10 weeks). In the rabbit, oligospermia did not occur until 10 weeks after treatment (Text-fig. 2), and this time was probably a reflection of the overall duration of spermatogenesis. Histological sections of both rat and rabbit testis, 24 days after treatment with Busulphan, show a similar state of depletion (Plate 1). These results support the view that the timing of spermatogenesis in the two species is similar.

The action of the branched-chain monofunctional compound, IMs (Textfig. 3) resembles that of Busulphan and TEM where early stages in spermatogenesis are also affected. There is some evidence of increased morphological abnormalities in spermatozoa during the 6 th to 7 th week but without diminution in count or less of motility. In the rat, it has also been found that infertile spermatozoa appear about the 6 th week.

The simple straight-chain esters, mes and Mms, however, produced no change in the total numbers of spermatozoa in rabbit ejaculates (Text-fig. 4). There is as yet no supporting data on the fertility of the rabbit, but comparable doses to groups of rats caused sterility in the 2nd and 3rd weeks following treatment. The increased incidence of abnormal spermatozoa in rabbit semen, observed from the 6th week onwards, suggests that some action on earlier stages of spermatogenesis may have occurred. The normal spermatozoal count during Weeks 10 to 12 after treatment supports the view that spermatogonial phases are not readily susceptible to interference by these straight-chain esters.

\section{ACKNOWLEDGMENT}

The authors wish to thank W. McCabe and J. Morrison for their technical assistance.

\section{REFERENCES}

Bishop, M. W. H., Gampbell, R. G., Hancock, J. L. \& Walton, A. (1954) Semen characteristics and fertility in the bull. $\mathcal{F}$. agric. Sci. 44, 227.

BLom, E. (1950) Om Bedommelsen af Tyresperma. Mortensen, Copenhagen.

Bock, M. \& JAckson, H. (1957) The action of triethylenemelamine on the fertility of male rats. Brit. 7. Pharmacol. 12, 1. 
Cattenach, B. M. \& Edwards, R. G. (1958) The effects of triethylenemelamine on the fertility of male mice. Proc. roy. Soc. Edinb. 67B, 54.

Glover, T. D. (1959) Experimental induction of seminal degeneration in rabbits. Studies on Fertility, 10,80 .

Glover, T. D. (1960) Spermatozoa from the isolated cauda epididymis of rabbits and some effects of artificial cryptorchidism. 7. Reprod. Fertil. 1, 121.

Heller, M. (1948) The testis. Histopathology of Irradiation, p. 550. National Nuclear Energy Series. McGraw Hill, New York.

JACkson, H., Fox, B. W. \& CRAIG, A. W. (1959) The effect of alkylating agents on male rat fertility. Brit. 7. Pharmacol. 14, 149.

Jackson, H., Fox, B. W. \& Craig, A. W. (1961) Antifertility substances and their assessment in the male rodent. 7. Reprod. Fertil. 2, 447.

Macirone, C. \& Walton, A. (1938) Fecundity of male rabbits as determined by 'Dummy matings'. 7. agric. Sci. 28, 122.

Ross, W. C. J. (1962) Biological alkylating agents. Butterworths, London.

Steinberger, E., Nelson, W. O., Boccabeli.A, A. \& Dixon, W. J. (1959) The radiomimetic effect of triethylenemelamine on reproduction in the male rat. Endocrinology, 65, 40.

Walton, A. (1958) Improvement in the design of an artificial vagina for the rabbit. F. Physiol. 143, $26 \mathrm{P}$. 


\section{EXPLANATION OF PLATE 1}

Fic. 1. Section of normal rabbit testis tubule.

Fig. 2. Twenty-four days after treatment of rabbit with $40 \mathrm{mg} / \mathrm{kg}$ Busulphan showing almost complete absence of spermatogonia and pachytene spermatocytes.

Frg. 3. Section of normal rat testis tubule.

Frg. 4. Twenty-four days after treatment of rat with $10 \mathrm{mg} / \mathrm{kg}$ Busulphan. A state of depletion comparable to that in Fig. 2 indicates that the maturation depletion is occurring at a similar rate in the two species. 
PLITE

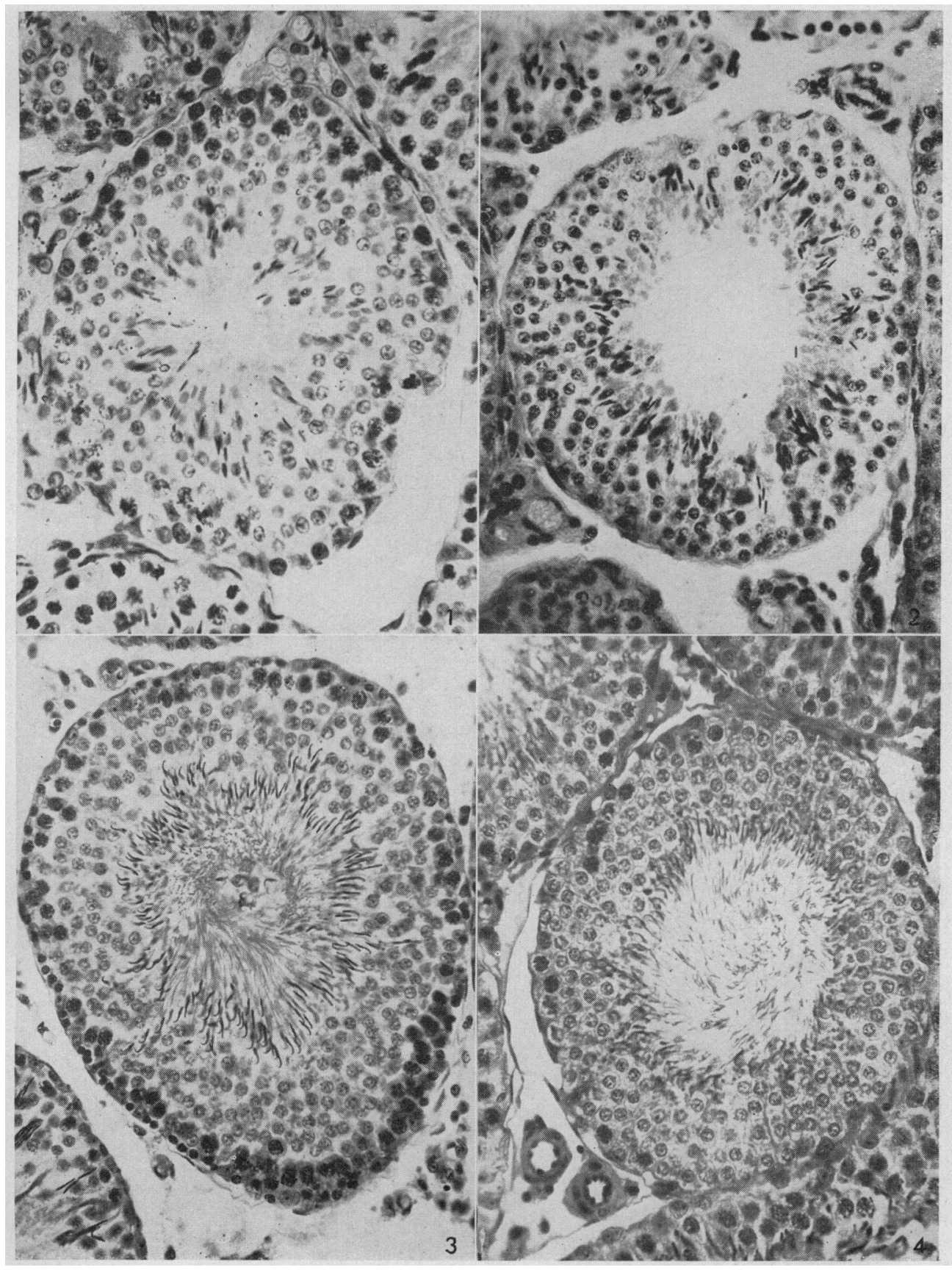

(Facing p. 22) 